LWSA

PAPER - OPEN ACCESS

Studi Pintu Masuk Utama Dermaga Pelabuhan Danau Terhadap Kenyamanan Penumpang Studi Kasus: Pelabuhan Ajibata, Danau Toba
Author
: Nelson M Siahaan
DOI
: 10.32734/lwsa.v1i2.212
Electronic ISSN
: 2654-7066
Print ISSN
: 2654-7058

Volume 1 Issue 2 - 2018 TALENTA Conference Series: Local Wisdom, Social and Arts

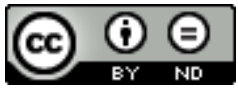

This work is licensed under a Creative Commons Attribution-NoDerivatives 4.0 International License.

Published under licence by TALENTA Publisher, Universitas Sumatera Utara
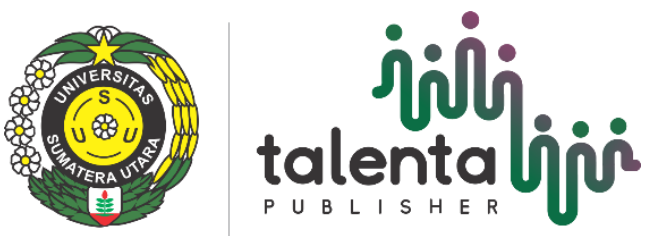


\title{
Studi Pintu Masuk Utama Dermaga Pelabuhan Danau Terhadap Kenyamanan Penumpang
}

\author{
Studi Kasus: Pelabuhan Ajibata, Danau Toba
}

\author{
Nelson M. Siahaan ${ }^{\mathrm{a}}$, Natalia R.E. Hutajulu ${ }^{\mathrm{a}}$ \\ ${ }^{a}$ Departemen Arsitektur Fakultas Teknik Universitas Sumatera Utara, Medan, Indonesia, 20155
}

nelson@usu.ac.id

\begin{abstract}
Port of Ajibata is the main entrance which connects Ajibata with Tomokin Toba Lake. The port has a limited capacity and a lack of service to support passenger needs.This research is aimed to find out how the port meets the passenger comfort levels and the factors that could meet the passenger comfort levels. Qualitative descriptive research method is used in this study. The respondents were 100 passengers which were chosen by using an incidental sampling technique. The data was collected by using questionnaire and documentation. Observation technique was also used to get a description of the real condition in port of Ajibata. The result showed that, the condition of passenger comfort in port of Ajibata is fair. Furthermore, the factors are very important to be considered and recommended: safety (55\%), accessibility from the land side (24\%), aesthetic senses (9\%), weather (5\%), accessibility from the lake side $(3 \%)$, cleanliness $(3 \%)$, noise $(0 \%)$, and aroma $(0 \%)$. The aim of the study is expected to be references to develop port of Ajibata, especially for facilities and infrastructure regarding to the safety and accessibility from the land side which considerably affect the passanger comfort.
\end{abstract}

Keywords: Entrance; port; lake harbour; passenger confort

\section{Pendahuluan}

Perairan Danau Toba membutuhkan pelabuhan sebagai prasarana transportasi air menghubungkan antar kabupaten di kawasan Danau Toba, khususnya Pulau Samosir dengan daerah di luar Pulau Samosir. Pelabuhan Ferry Ajibata adalah salah satu pelabuhan yang ada di Danau Toba yang menghubungkan Ajibata di Kabupaten Tobasa dengan Tomok di Kabupaten Samosir. Sebagai satu-satunya pintu masuk utama yang sangat sibuk dengan jumlah kunjungan penumpang dan muatan barang yang cukup banyak, pelayanan yang diberikan oleh dermaga Ajibata masih jauh dari harapan. Kondisi ini disebabkan karena beberapa permasalahan seperti: daya tampung dermaga yang terbatas dengan intensitas arus penumpang dan barang yang terus meningkat, durasi waktu penyeberangan yang lama disebabkan oleh keterbatasan jumlah unit kapal dan antrian, keterbatasan lahan parkir di dermaga menyebabkan persilangan (crossing) tidak beraturan padasaat penumpang naik ataupun turun ferry/kapal.

Dermaga kapal adalah bagian dari sarana perairan yang memiliki nilai "ruang" arsitektural berupa garis batas/peralihan antara darat dan air. Oleh karena itu, bentuk dankondisi geografis dermaga haruslah menawarkan 
pengalaman ruang yang menarikdan baik bagi setiap pengguna jasa dermaga kapal. Pengalaman ruang yang menarik dan baik ini akan sangat mempengaruhi kenyamanan penumpang melakukan kegiatan penyeberangan.

Aspek kenyamanan dermaga berkaitan erat dengan kelengkapan fasilitas baik di sisi darat (penumpang), maupun dari sisi danau (kapal). Kenyamanan dan perasaan nyaman adalah penilaian komprehensif seseorang terhadap lingkungannya. Manusia menilai kondisi lingkungan berdasarkan rangsangan yang masuk ke dalam dirinya melalui keenam indera melalui syaraf dan dicerna oleh otak untuk dinilai. Suwarto [1] melihat aspek-aspek yang mempengaruhi kenyamanan suatu dermaga: (a) sarana dan prasarana yang meliputi fasilitas pelabuhan, fasilitas dermaga, dan jenis kapal yang beroperasi di pelabuhan tersebut (b) aksesibilitas yang berkaitan dengan tata guna lahan dan sistem jaringan transportasi, dan (c) sumber daya manusia yang memenuhi standar kompetensi. Sementara itu, Hakim [2] menyebutkan faktor-faktor yang mempengaruhi kenyamanan adalah: (a) aksesibilitas dari sisi darat, berupa pola sirkulasi penumpang dari satu ruang ke ruang lain meliputi sirkulasi manusia dan kendaraan (b) aksesibilitas dari sisi danau yakni pola pergerakan kapal (c) kebisingan (d) keamanan, yang terkait dengan bahan material konstruksi (e) keindahan (f) kebersihan (g) iklim dan (h) aroma.

Triatmodjo [3] menyatakan dermaga adalah bangunan pada pelabuhan yang digunakan untuk merapat dan menambatkan kapal untuk melakukan bongkar muat barang dan menaik-turunkan penumpang. Sebagai titik temu dimana terjadi pergantian moda transportasi, dan juga sebagai area peralihan antara darat dan air, sudah barang tentu terjadi banyak aktifitas pada dermaga.Studi ini mengkaji; (1) sejauh mana dermaga Ajibata dapat memenuhi tingkat kenyamananpenumpang, dan (2) faktor-faktor apa saja yang dapat memenuhi kenyamanan penumpang.

\section{Metodologi}

Lokasi studi adalah dermaga Pelabuhan Ajibata, Danau Toba (Gambar 1). Jenis studi ini merupakan deskriptif kualitatif. Populasinya merupakan penumpang berusia 17 hingga $>45$ tahun yang mengunjungi Dermaga Pelabuhan Ajibata, Danau Toba. Sampel yang dipilih adalah sebanyak 100. Skala Likert digunakan untuk mengukur penilaian dan harapan penumpang

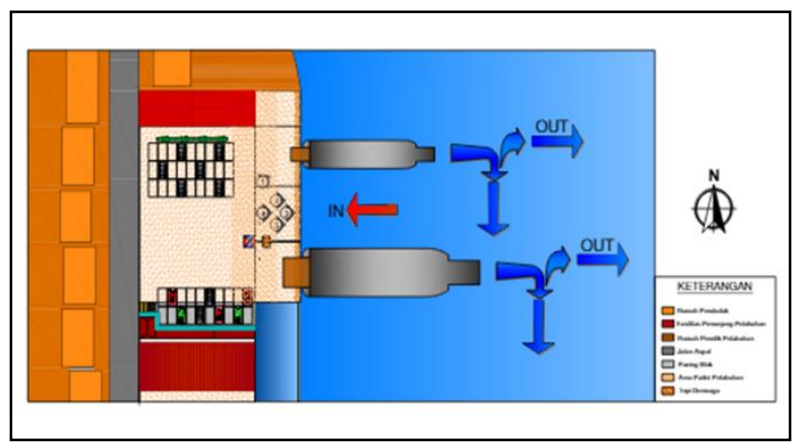

Gambar 1. Peta lokasi dermaga ajibata ${ }^{[5]}$

Tabel 1. memperlihatkan variabel, indikator, dan metode yang digunakan di dalam studi ini.Data di dalam studi ini, berupa:

1) data primer diperoleh dengan teknik observasi, kuesioner, foto dan wawancara, serta

2) data sekunder diperoleh dari Dinas Perhubungan Kabupaten Tobasir, buku, jurnal, media elektronik, dan lain sebagainya.

Tabel 1.Variabel, Indikator \& Metode Studi

\begin{tabular}{lll}
\hline Indikator & Metode \\
\hline$\bullet$ aksesibilitas dari sisi darat & \\
$\bullet$ aksesibilitas dari sisi danau & \\
$\bullet$ & kebisingan \\
\hline
\end{tabular}




\begin{tabular}{|c|c|c|}
\hline Kenyamanan & $\begin{array}{l}\text { - keamanan } \\
\text { - keindahan } \\
\text { - kebersihan } \\
\text { - iklim } \\
\text { - aroma } \\
\text { - tempat duduk } \\
\text { - penerangan } \\
\text { - jalur pejalan kaki } \\
\text { - tempat sampah } \\
\text { - tanda penunjuk } \\
\text { - toilet umum } \\
\text { - vegetasi } \\
\text { - tempat parkir }\end{array}$ & $\begin{array}{l}\text { - kuesioner. } \\
\text { - wawancara. } \\
\text { - observasi. } \\
\text { - foto. }\end{array}$ \\
\hline
\end{tabular}

Sumber: Project For Public Space [3]

\section{Hasil dan Pembahasan}

Dari studi, 100 responden yang berkunjung di dermaga Ajibata didominasi oleh penumpang laki-laki (60\%). Selanjutnya, penumpang berusia 17-25 tahun (51\%) lebih sering mengunjungi dermaga dibandingkan dengan penumpang berusia diatas 45 tahun (9\%). Hasil studi juga menunjukkan bahwa tingkat pendidikan penumpang tertinggi adalah S1 (70\%), sedangkan mayoritas penumpang memiliki pekerjaan sebagai pegawai $(40 \%)$ dengan penghasilan antara satu juta upiah sampai dengan lima juta rupiah $(65 \%)$.

4. Secara umum, penumpang berkunjung ke dermaga Ajibata hanya menghabiskan waktu antara1-5 jam / minggu (86\%) dengan waktu yang tidak tetap dalam seminggu (93\%). Kunjungan penumpang biasanya lebih banyak bersama rombongan (65\%) dengan menggunakan moda transporatasi mobil $(80 \%)$, serta waktu berkunjung pada sore hari $(43 \%)$.

Tabel 2, memperlihatkan bahwa umumnya penilaian penumpang tentang aksesibilitas dari sisi darat secara kualitatif cukup baik (CB). Sementara, observasi di dermaga, jumlah ruang parkir terbatas dan kepadatan jumlah kendaraan pribadi penumpang kapal yang besar menyebabkan kesulitan akses keluar masuk area dermaga dan mengakibatkan terjadinya crossing (persilangan) sirkulasi pada saat embarkasi dan debarkasi penumpang

Tabel 2. Aksesibilitas dari sisi darat

\begin{tabular}{|c|c|c|c|c|c|c|c|}
\hline \multirow{2}{*}{ Penilaian } & \multicolumn{6}{|c|}{ Dalam Persentase (\%) } & \multirow[t]{2}{*}{ Jumlah } \\
\hline & SB & 1 & & CB & KB & TB & \\
\hline Area parkir $\rightarrow$ Dermaga & 1 & \multicolumn{2}{|c|}{22} & 47 & 26 & 4 & 100 \\
\hline Dermaga $\rightarrow$ Kapal & 1 & \multicolumn{2}{|c|}{22} & 51 & 24 & 2 & 100 \\
\hline Kapal $\rightarrow$ Dermaga & 1 & \multicolumn{2}{|c|}{24} & 53 & 20 & 2 & 100 \\
\hline \multirow{2}{*}{ Harapan } & \multicolumn{6}{|c|}{ Dalam Persentase $(\%)$} & Jumlah \\
\hline & SP & $\mathbf{P}$ & \multicolumn{2}{|c|}{$\mathbf{C P}$} & KP & $\mathbf{T P}$ & \\
\hline Area parkir $\rightarrow$ Dermaga & 63 & $\begin{array}{l}2 \\
6\end{array}$ & \multicolumn{2}{|l|}{8} & 2 & 1 & 100 \\
\hline Dermaga $\rightarrow$ Kapal & 62 & $\begin{array}{l}2 \\
8\end{array}$ & \multicolumn{2}{|l|}{5} & 3 & 1 & 100 \\
\hline Kapal $\rightarrow$ Dermaga & 62 & $\begin{array}{l}3 \\
0\end{array}$ & \multicolumn{2}{|l|}{5} & 3 & 0 & 100 \\
\hline
\end{tabular}


Penilaian penumpang mengenaikualitas akses masuk dari sisi danau adalah cukup baik seperti tampak pada tabel 3. Hasil pengamatan langsung (observasi) di lapangan juga cukup baik. Karena sirkulasi pergerakan kapal dalam mencapai dermaga ketika bersandar dan manuver ketika berlayar sudah sesuai dengan standar International Maritim Organization (IMO), yaitu dengan melakukan perputaran dan zig-zag.

Tabel 3. Aksesibilitas dari sisi danau

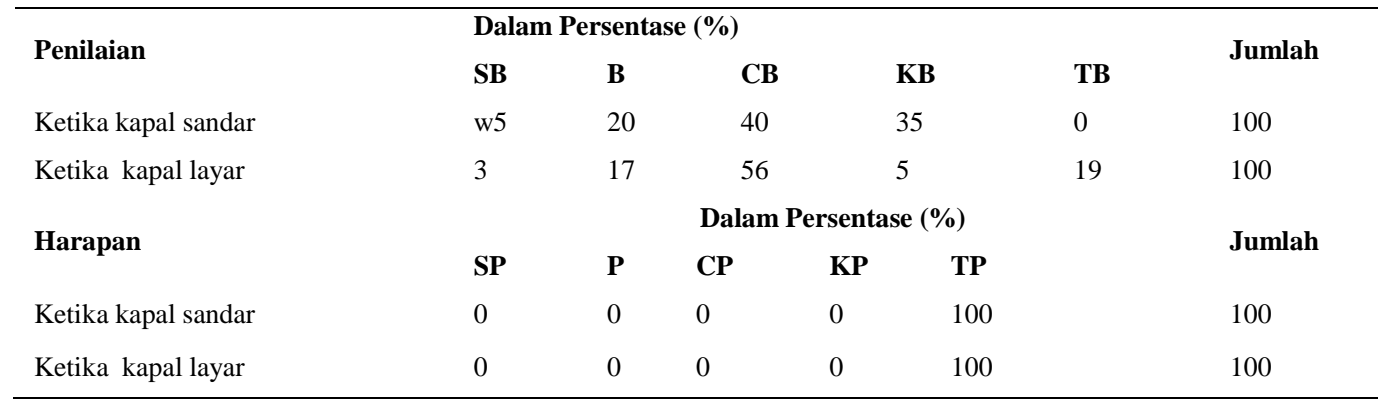

Tabel 4 menunjukkan penilaian penumpang akan kondisi iklim yaitu cukup baik. Hasil pengamatan langsung (observasi) di lapangan memperlihatkankan kondisi iklim ketika curah hujanmengakibatkan kualitas dermaga buruk akibat akan becek dan licin dikarenakan material dermaga berupa tanah berbatu-batu, sedangkan ketika terik sinar matahari hanya sedikit naungan/teduhan yang dapat melindungi penumpang, serta kurangnya vegetasi untuk dapat mengurangi angin yang berkecepatan tinggi.

Tabel 4. Penilaian Iklim

\begin{tabular}{|c|c|c|c|c|c|c|c|c|}
\hline \multirow{2}{*}{ Penilaian } & \multicolumn{7}{|c|}{ Dalam Persentase (\%) } & \multirow{2}{*}{ Jumlah } \\
\hline & SB & & & CB & & KB & TB & \\
\hline Panas matahari & 1 & & & 51 & & 10 & 0 & 100 \\
\hline Angin kecepatan tinggi & 2 & & & 54 & & 4 & 0 & 100 \\
\hline Curah hujan & 5 & & & 46 & & 7 & 1 & 100 \\
\hline \multirow{2}{*}{ Harapan } & \multicolumn{7}{|c|}{ Dalam Persentase $(\%)$} & \multirow{2}{*}{ Jumlah } \\
\hline & SP & $\mathbf{P}$ & $\mathbf{C P}$ & & $\mathbf{K P}$ & & $\mathbf{T P}$ & \\
\hline Panas matahari & 57 & 26 & 8 & & 8 & & 1 & 100 \\
\hline Angin kecepatan tinggi & 59 & 26 & 9 & & 5 & & 1 & 100 \\
\hline Curah hujan & 58 & 30 & 6 & & 5 & & 1 & 100 \\
\hline
\end{tabular}

Tabel 5 menunjukan penilaian penumpang akan kebisingan adalah cukup baik. Observasi di lapangan ditemukan bahwa dermaga tidak mempunyai jenis tanaman-tanaman yang bervariasi untuk membantu mengurangi kebisingan.

Tabel 5. Tabulasi Penilaian Kebisingan

\begin{tabular}{|c|c|c|c|c|c|c|}
\hline \multirow{2}{*}{ Penilaian } & \multicolumn{5}{|c|}{ Dalam Persentase (\%) } & \multirow{2}{*}{ Jumlah } \\
\hline & SB & B & CB & KB & TB & \\
\hline Di area parkir & 4 & 25 & 54 & 12 & 5 & 100 \\
\hline Kapal bersandar & 2 & 29 & 56 & 10 & 3 & 100 \\
\hline Kapal berlayar & 3 & 28 & 58 & 7 & 4 & 100 \\
\hline \multirow{2}{*}{ Harapan } & \multicolumn{5}{|c|}{ Dalam Persentase (\%) } & \multirow{2}{*}{ Jumlah } \\
\hline & SP & $\mathbf{P}$ & $\mathbf{C P}$ & $\mathbf{K P}$ & $\mathbf{T P}$ & \\
\hline Di area parkir & 5 & 4 & 16 & 27 & 5 & 100 \\
\hline Kapal bersandar & 5 & 4 & 15 & 30 & 6 & 100 \\
\hline Kapal berlayar & 5 & 4 & 17 & 28 & 22 & 100 \\
\hline
\end{tabular}


Lebih jauh, tabel 6 menunjukkan penilaian penumpang akan kebersihan adalah cukup baik. Sebaliknya, pengamatan langsung di demarga ditemukan kondisi kebersihan dermaga belum sesuai kriteria, karena terdapat bak sampah yang letaknya berdekatan dengan dermaga, terdapat tumpukan sampah di sisi dermaga dan di air danau.

Tabel 6. Tabulasi Penilaian Kebersihan

\begin{tabular}{|c|c|c|c|c|c|c|}
\hline & \multicolumn{5}{|c|}{ Dalam Persentase (\%) } & \multirow{2}{*}{ Jumlah } \\
\hline & SB & B & CB & KB & TB & \\
\hline Keberadaan sampah & 7 & 18 & 59 & 15 & 1 & 100 \\
\hline Ketersediaan sampah & 5 & 9 & 63 & 22 & 1 & 100 \\
\hline \multirow{2}{*}{ Harapan } & \multicolumn{5}{|c|}{ Dalam Persentase (\%) } & \multirow{2}{*}{ Jumlah } \\
\hline & SP & $\mathbf{P}$ & $\mathbf{C P}$ & $\mathbf{K P}$ & $\mathbf{T P}$ & \\
\hline Keberadaan sampah & 42 & 32 & 16 & 7 & 3 & 100 \\
\hline Ketersediaan sampah & 45 & 35 & 14 & 6 & 0 & 100 \\
\hline
\end{tabular}

Tabel 7 memperlihatkan bahwa penilaian penumpang akan keindahan disekitar pelabuhan cukup baik. Observasi menemukan bahwa kondisi kebersihan dermaga juga cukup baik. Akan tetapi,diperlukan penambahan vegetasi untukmemayungi penumpang dari gangguan iklim, penambahan tempat duduk serta penambahan penerangan pada dermaga untuk keindahan.

Tabel 7. Penilaian Keindahan

\begin{tabular}{lllllll}
\hline \multirow{2}{*}{ Penilaian } & \multicolumn{7}{c}{ Dalam Persentase (\%) } & \multicolumn{2}{c}{ Jumlah } \\
& SB & B & CB & KB & TB & \\
Lampu-lampu & 3 & 13 & 49 & 31 & 4 & 100 \\
Pohon-pohon (vegetasi) & 3 & 13 & 52 & 30 & 2 & 100 \\
Tempat duduk & 3 & 14 & 60 & 23 & 0 & 100 \\
Harapan & Dalam Persentase (\%) & & & & Jumlah \\
Lampu-lampu & SP & P & CP & KP & TP & \\
Pohon-pohon (vegetasi) & 76 & 18 & 6 & 0 & 0 & 100 \\
Tempat duduk & 66 & 34 & 0 & 0 & 0 & 100 \\
\hline
\end{tabular}

Tabel 8 memperlihatkan penilaian kurang baik dari penumpang akan keamanan demarga. Hasil pengamatan memperlihatkan bahwa kualitas keamanan dermaga masih kurang baik dari aspek bentuk, jenis dan material yang belum memenuhi standar keselamatan para penumpang.

Tabel 8. Penilaian Keamanan

\begin{tabular}{lllcccc}
\hline Penilaian & SB & B & CB & KB & TB & Jumlah \\
Pagar pembatas & 2 & 7 & 31 & 42 & 18 & 100 \\
Lantai dermaga & 0 & 8 & 43 & 47 & 2 & 100 \\
Elevasi dermaga & 1 & 10 & 40 & 48 & 1 & 100 \\
Harapan & & & Dalam Persentase (\%) & Jumlah \\
Pagar pembatas & SP & $\mathbf{P}$ & $\mathbf{C P}$ & $\mathbf{K P}$ & $\mathbf{T P}$ & \\
Lantai dermaga & 73 & 18 & 8 & 1 & 0 & 100 \\
\hline
\end{tabular}




\begin{tabular}{lllllll}
\hline Elevasi dermaga & 75 & 17 & 7 & 1 & 0 & 100
\end{tabular}

Penumpang menilai aroma di sekitar dermaga cukup baik (tabel 9). Observasi menunjukkan kekurangan yang ditemukan di lapangan seperti adanya tumpukan sampah di sudut tertentu dan aroma air danau mempengaruhi kenyamanan penumpang.

Tabel 9. Penilaian Aroma

\begin{tabular}{lllcccc}
\hline Penilaian & \multicolumn{3}{c}{ Dalam Persentase (\%) } & Jumlah \\
Tumpukan sampah & SB & B & CB & KB & TB & 100 \\
Drainase & 1 & 16 & 55 & 20 & 8 & 100 \\
Air danau toba & 1 & 15 & 55 & 21 & 8 & 100 \\
Harapan & 11 & 31 & 46 & 7 & 5 & Jumlah \\
Tumpukan sampah & & & Dalam Persentase (\%) & TP & 100 \\
Drainase & SP & $\mathbf{P}$ & $\mathbf{C P}$ & $\mathbf{K P}$ & 3 & 100 \\
Air danau toba & 9 & 11 & 32 & 45 & 32 & 100 \\
\hline
\end{tabular}

Dari keseluruhan aspek penentu kenyamanan dermaga ini, studi menunjukan bahwa kualitas keamanan dermaga meliputi pagar pembatas, lantai dan elevasi dermaga 55\% responden menilai sangat penting. Kualitas keamanan ini merupakan persentae terbesar dari faktor yang lain. Artinya faktor keamanan adalah prioritas utama, mengingat material dermaga yang masih berupa tanah, tidak adanya pagar, sehingga perlu diperhatikan.

Aksesibilitas dari sisi darat merupakan faktor kedua yang penting untuk diperhatikan dengan $24 \%$ responden yang memilih. Mengingat area parkir yang sempit dan jaraknya berdekatan dengan dermaga, sehingga mengakibatkan crossing yang tidak beraturan dan kapasitas area parkir yang terbatas untuk menampung jumlah penumpang yang semakin meningkat. Selain itu10\% responden memilih faktor keindahan sebagai faktor ketiga yang penting. Hal ini dapat dilihat dari kondisi dermaga yang masih minim penerangan, tempat duduk, dan pohon-pohon. Sementara, faktor iklim (5\%) faktor keempat memerlukan vegetasi untuk dapat melindungi penumpang dari gangguan iklim seperti; panasmatahari, curah hujan yang tinggi, dan angin yang berkecepatan tinggi.Aksesibilitas dari sisi danau merupakan faktor kelima yang penting yaitu 3\% responden. Hal ini dikarenakan dua indikator yang mempengaruhi penilaian, antara lain ketika kapal bersandar sering mengalami benturan pada dermaga berupa tanah berbatu-batu. Sebaliknya, ketika kapal berlayar, para anak buah kapal terlebih dahulu memberikan penyangga papan ke dermaga untuk melapisi ramp door kapal, dan ketika lepas sandar kembali melepas papan pelapis ramp door dari dermaga yangberakibat kurang optimal keleluasan kapal dalam mencapai dermaga.

Faktor kebersihan (3\%) sebagai faktor keenam yang penting. Penempatan tempat sampah yang tidak memperhatikan estetika dermaga, dengan posisi bak sampah yang berdekatan dengan dermaga serta tumpukan sampah yang berserakan, dan jumlah tempat sampah yang masih minim telah menjadikan kondisi kebersihan dermaga kurang optimal.

\section{Kesimpulan}

Studi ini menunjukkan bahwa aksesibilitas dari sisi darat dermaga danau Toba Ajibatasudah cukup baik, namun dari observasi tampak kondisi akses dermaga masih kurang baik, terutama berkaitan dengan penataan area parkir yang sempit dan tidak adanya rambu lalu lintas. Berdasarkan tingkat kepentingan (prioritas), faktor-faktor yang perlu diperhatikan dalam upaya peningkatan kenyamanan penumpang adalah:

1. Keamanan menjadi faktor utama perlu mendapat perhatian dengan prosentase tingkat kepentingan (55\%) terutama terkait dengan material konstruksi dermaga. 
2. Aksesibilitas dari sisi darat menjadi faktor kedua yang perlu untuk diperhatikan (24\%). Hal ini terkait dengan tata ruang parkir yang masih buruk terutama zonasi parkir kendaraan bus penumpang, truk, dan kendaraan penumpang menimbulkan penyilangan sirkulasi/trafficyang tidak beraturan.

Sedangkan berturut-turut tentu perlu juga mendapat perhatian untuk kenyamanan adalah keindahan dengan bobot (9\%), iklim (5\%),

\section{References}

[1] Suwarto, A. (2009). Penelitian kinerja pelayanan pelabuhan penyeberangan perintis Taipa, Sulawesi Tengah. Jurnal Transportasi Darat, 11 (3): $140-151$.

[2] Hakim, R. \& Utoma, H. (2003). Komponen perancangan arsitektur lanskap. Prinsip-unsur dan aplikasi desain. Jakarta: Bumi Aksara.

[3] Triatmodjo, B. (1993). Pelabuhan. Yogyakarta: Beta Offset.

[4] Project for Public Spaces (2000) How to Turn a Place Around: a Handbook for Creating Successful Public Spaces, PPS Inc.: New York.

[5] BAPPEDA dan BPS Kabupaten Toba Samosir. (2011) Kecamatan Ajibata dalam Angka Tahun 2011. Toba Samosir: Pemerintah Kabupaten Samosir 